\title{
A Comprehensive Definition and Systematic Subdivision of Hydrography
}

Lars SCHILLER ${ }^{1}$, Volker BÖDER†, Hans Werner SCHENKE ${ }^{2}$, Germany

${ }^{1}$ HafenCity University, ${ }^{2}$ Alfred Wegener Institute

Topic: $\mathrm{P}$ - poster presentation

\section{INTRODUCTION}

The concept of hydrography is subject to constant change. The science continues to develop, its methods develop further, the view on the object of investigation changes, the objective is formulated differently. Someone who uses the term 'hydrography' today means most likely something different than he did 20 years ago when he used this term too. Perhaps he is even aware of it.

But actually, is there a guarantee that speakers and listeners have the same concept of hydrography? That the two parties share the same idea of hydrography? Unfortunately, no.

Why is that? Why could technical communication fail?

The main reason is that the concept of hydrography is indeed defined - for example, in general language encyclopaedias, technical dictionaries and standards - , but that these definitions do not always express the same thing, they are focused on different aspects, and sometimes they are even contradictory. Normally, in a conversation about hydrography it is not mentioned to which definition one refers.

Another reason is that the definitions - especially if they have been written by experts in hydrography - do not meet the requirements that lexicographers have on a definition. To make matters worse, very few definitions are clear and vivid.

Finally, it plays a role that the term 'hydrography' does not only denote the scientific discipline, but the term can take at least ten more different common meanings.

Therefore there is the need to present an up-to-date definition.

This newly presented definition is comprehensive and meets the lexicographic requirements. It is intelligible to everybody, clear and vivid, and it is completed by a systematic subdivision according to the object of investigation.

\section{ONE TERM WITH ELEVEN MEANINGS}

The term 'hydrography' seems to be very specific, but it is used in several meanings. After an extensive consultation of German and English encyclopaedias and general language dictionaries as well as after a wide-ranging literature review - also of non-hydrographic literature - eleven now common concepts were identified, all denominated with the (homonymous) term 'hydrography'.

In addition, some obsolete meanings were found, and concepts that are falsely denominated by the term. A total of 19 different concepts were identified. 
In a technical language dictionary eleven current meanings could be included.

hy•drog•ra•phy -ies, | hî'drägrəfē | noun,

1 no pl., science of surveying of bodies of water and waters-related information;

2 no pl., a) depth measurement of waters (esp. of oceans), bathymetry;

b) surveying of bodies of water;

3 no pl., a) descriptive hydrology; b) characteristic features of bodies of water, descriptive set of waters-related data and information;

4 no pl., (register of the) totality of the waters in an area, waters index;

5 no pl., a) map element; b) cartographic depiction of waters;

6 shape of the bottom of a water, topography covered by water, morphology;

7 a) no pl., art technique; b) artwork.

The fact that the term has so many different meanings makes technical communication more complicated and can lead to misunderstandings. Even hydrographers use the term in different meanings. But there is another problem: The concept of hydrography as a science is not clearly defined.

\section{THE CONCEPT OF HYDROGRAPHY}

The concept of hydrography as a science is hardly defined in common language dictionaries. But there are several attempts by experts to define the concept of hydrography. For example, the United Nations presented a definition in 1978 that is still quoted today (UN 1978, p. 67). Also the definition in the Hydrographic Dictionary published in 1994 by the International Hydrographic Organization (IHO) is popular (IHO 1994, p. 108). Finally, the IHO has introduced a revised definition in 2009. This definition has been adopted after an extensive consultation process of the member countries of the IHO; it can therefore be considered as the official definition based on a consensus (IHO 2009, p. 38).

An evaluation of the above mentioned definitions - and of other definitions - shows that experts do not necessarily share the same view. All definitions present a different picture of hydrography.

\section{The definition by the IHO}

"Hydrography is the branch of applied sciences which deals with the measurement and description of the physical features of oceans, seas, coastal areas, lakes and rivers, as well as with the prediction of their change over time, for the primary purpose of safety of navigation and in support of all other marine activities, including economic development, security and defence, scientific research, and environmental protection" (IHO 2009, p. 38).

\section{Significant points of criticism}

Compared to the definition of 1994 this definition shows a more modern understanding of hydrography. This is also reflected in the length of the sentence. The sentence consists of 64 words. Linguists say that the limit should be 25 words, otherwise a sentence is not immediately evident.

There are two main points of criticism: This definition provides only an incomplete understanding of the concept. And this definition does not meet the requirements set by lexicographers.

Why does the definition not describe the full concept? And why does it show formal mistakes? 
According to this definition, hydrography is an "applied science". This statement should make it possible to classify hydrography. Unfortunately, the classification is much too vague. There are so many applied sciences. Therefore, it is necessary to name the hypernym. And it should be mentioned that there are also theoretical shares.

Then it says that hydrography deals with the "measurement and description". The question is: Why only 'description'? Why not also 'depiction'? It is not only about a spoken or written representation, it is also about a visualisation. It is important to mention the cartographic aspect.

Furthermore it says that only the "physical features" of waters are described. It is hard to imagine what physical features are. This is certainly not wrong, but unfortunately it is unclear and abstract. Neither the chemical properties are mentioned nor the geographical relationship.

For the first time the IHO does not only focus on the sea: "oceans, seas, coastal areas, lakes and rivers" are listed in the definition. The intention is to express that hydrography examines all waters. But this is not said. And it is not explained what is studied in detail, what qualitative and quantitative investigations are carried out. And why are only the coastal areas mentioned, but not the shorelines? It is not correct to make a list, but not to list all items.

Although the definition refers to all waters, it then says "marine activities". This restriction to the marine sphere is not logical. The statements are not consistent.

It is a real improvement that the "changes over time" are mentioned in this definition for the first time. However, it is only about the "prediction". But hydrographers are also interested in the comparison between two states.

The last point is the exemplary reference to the reasons for hydrography ("for the primary purpose ... and ... including"). It is good to explain the motivation to get an idea of what the activities are. But the way this is done is too random and just exemplary. The definition does not explain, but it raises new questions.

Therefore, it is necessary to write a new definition.

\section{HOW TO DO BETTER?}

There is a lot to criticise. But the question is, after all, how to do it better. How is it possible to define the concept of hydrography in accordance with lexicographic requirements?

There are a few criteria to write a formally correct definition. In other words: There are several ways to write a definition (cf. Schaeder 2007). In a content definition the hypernym has to be mentioned, and the specific distinctive features have to be named. In a scope definition and in an inventory definition hyponyms are listed. The list "seas, lakes and rivers" would be good for a scope definition. When the coastal zones and shorelines are added, it is an inventory definition.

But there are also wrong definitions. Thus, for example, a definition can be too wide or too narrow. If it says hydrography examines only the oceans the definition is too narrow, because the inland waters are forgotten. A definition is too wide, if it says that hydrography examines all waters, because that includes the groundwater. But to examine the groundwater is not the job of hydrographers, it is the job of hydrologists.

Before starting to write a definition, one should acquire some basic knowledge of lexicography. 
The task is not only to present a formally correct definition. The goal is also to define the concept comprehensively and vividly.

Therefore, it is necessary

- to name the hypernym in order to classify hydrography;

- to specify the distinctive features;

- to list all specific hyponyms, so that nothing is forgotten;

- to list the activities on the object of investigation.

This is best achieved by a systematic subdivision. Only then it is possible to create a clear and vivid definition. Besides, common language should be used in short sentences, and unknown words should be avoided.

\section{A NEW DEFINITION}

Hydrography is a branch of the science of surveying and geoinformation. It investigates the surface waters of the earth and collects the related data and information. Its goal is to expand the knowledge of waters in order to use them responsibly and safely and to protect the habitat. The practical engineering and geoscientific work is divided into three main fields of activity:

1. Surveying of waters, and recording of aquatic data;

2. Processing of the data, administering the data in information systems, and analysing the total set of data;

3. Visualising the waters on charts and in information systems, and informing about the waters.

After the examination of a surface water hydrography provides information about its current state and about past and future changes.

It makes statements about:

- the water depths in relation to a reference horizon,

- the positions of shoals,

- the positions of magnetic anomalies,

- the shape and structure of the bottom,

- the material composition of the bottom,

- the structure of the deeper soil layers,

- the location of deposits,

- the uniform change of the water level (tides),

- the short-term and long-term change of the water level (storm surge, sea level rise),

- the height profile of the water surface (orthometric height),

- the characteristics of waves,

- the characteristics of currents,

- individual parameters of the water column (temperature, salinity),

- the structure of the water body,

- the water quality (particle concentration, radioactivity),

- the natural and artificial objects in and on the waters,

- the traffic situation on the waters,

- the course of the water's limit,

- the course of boundaries within the waters,

- the nature of the adjacent land strip (coastal zone resp. shoreline). 


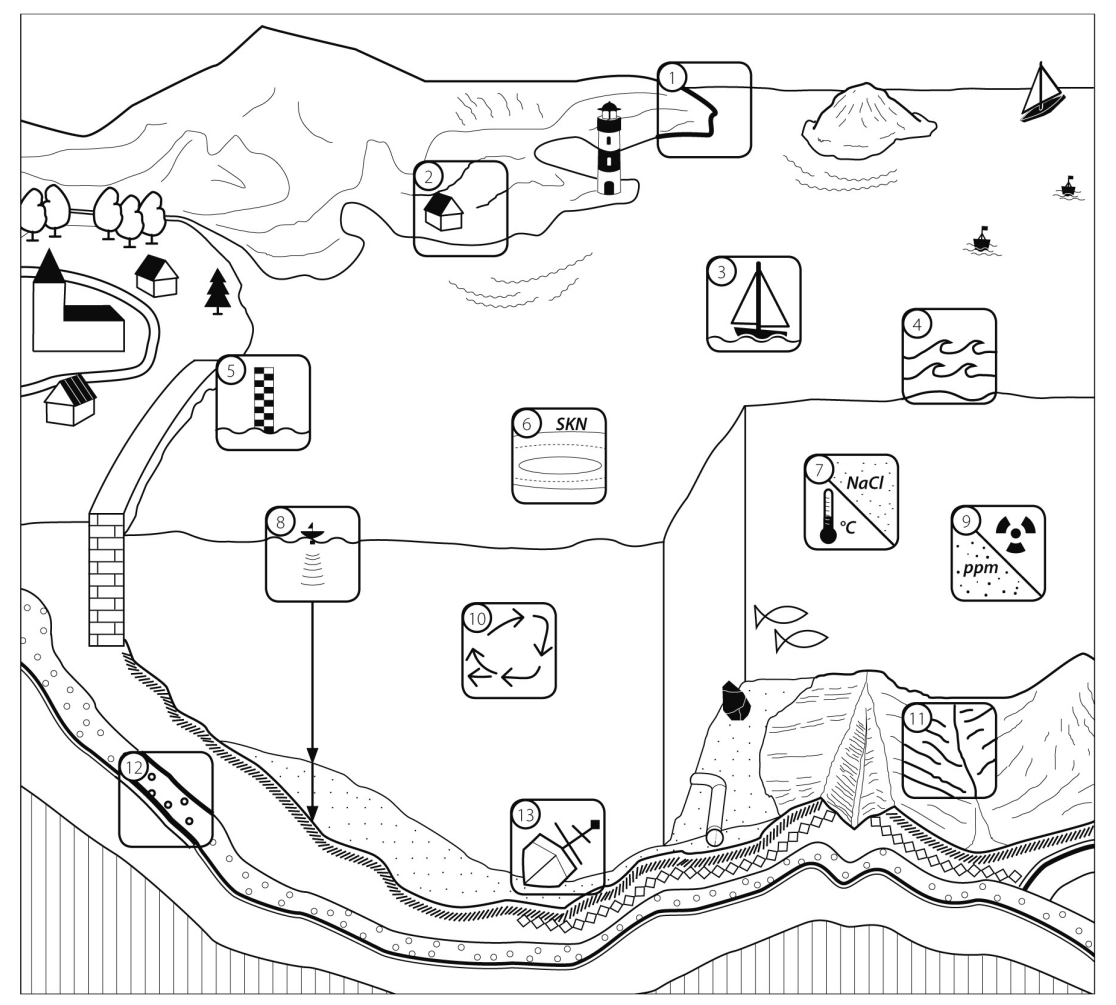

Object of investigation of hydrography

1. Course of the water's limit

2. Nature of the adjacent land strip (coastal zone resp. shoreline)

3. Traffic situation on waters

4. Characteristics of waves

5. Water level

6. Height profile of the water's surface (orthometric height)

7. Individual parameters of the water column (temperature, salinity)

8. Water depths

9. Water quality (particle concentration, radioactivity)

10. Characteristics of currents

11. Nature of the bottom

12. Structure of the deeper soil layers

13. Natural and artificial objects in and on the waters

\section{CONCLUSION}

This comprehensive definition of hydrography provides a complete understanding of the concept, and it meets the formal lexicographic requirements. The definition allows a clear technical communication. A scientist who delineates his conception in another way is able to specify in what sense he uses the term. For this he simply needs to work out the difference between the definition and his own understanding of the concept.

Also the intercultural aspect is important, for example, when hydrography shall be exported to other countries in the context of development assistance and capacity building. In these countries hydrography is still unknown and there are therefore no terms in national languages for it. This definition makes it possible to evoke a clear idea - and to create a new term in another language in a further step. Even to make it clear to a layman what hydrography is in his own language, this definition is very helpful. 


\section{REFERENCES}

IHO (1994): S-32 - Hydrographic Dictionary. Special Publication No. 32, Part 1, Vol. 1, English, Fifth edition; Monaco, IHB - International Hydrographic Bureau

IHO (2009): Proposal to Approve New Definition of Hydrography; in: IHO: 4th Extraordinary International Hydrographic Conference, June 2-4, 2009, Monaco, Report of Proceedings; pp. 38-40, Monaco, IHB - International Hydrographic Bureau

Schaeder, Bernhard (2007): Terminologie und Fachlexikographie; Materialienarchiv mit Skripten, online: http://www.uni-siegen.de/fb3/lissie/materialien/mschaeder.html?lang=de, last access:

August 15, 2010

UN - United Nations (1978): Report of the Group of Experts on Hydrographic Surveying and Nautical Charting; in: UN (1981): Second United Nations Regional Cartographic Conference for the Americas - Report of the Conference. Vol. I; Mexico City, September 3-14, 1979; E/CONF.71/3, pp. 63-96

\section{BIOGRAPHIES}

Lars SCHILLER graduated in Surveying Engineering from the University of Applied Sciences Hamburg in 2002. Since 2008 he has been working as a technical writer at a full service company for technical documentation where he is responsible for terminology management. In March 2012 he finished his second study in hydrography at the HafenCity Unversity in Hamburg, and presented his master thesis about the position of hydrography in a system of sciences.

Volker BÖDER graduated in Geodesy from the University of Hannover in 1994. His doctoral thesis from 2002 was about precise positioning and attitude determination in marine applications. He received his Assessor Degree from the Government of the Federal State of Lower Saxonia in 2005. Since 2005 he has been professor for practical geodesy and hydrography at the HafenCity University, Hamburg.

Hans Werner SCHENKE graduated in Geodesy from the University of Hannover in 1977. Since 1983 he has been Head of the Geodetic and Bathymetric Lab at the Alfred Wegener Institute in Bremerhaven and responsible for scientific bathymetry and geodetic programmes in polar regions. He is member of several international Committees for ocean mapping and undersea feature naming. Since 1999 he has been lecturer for GIS Hydrography at the Leibniz University Hannover and received an honorary professorship there in 2011.

\section{CONTACT DETAILS}

Lars Schiller

HafenCity University Hamburg

Schulteßdamm 35

22391 Hamburg

GERMANY

Tel.: +49 4074397323

E-mail: lars.schiller@hcu-hamburg.de 